\title{
Cerebral protection for transcatheter aortic valve implantation: A no brainer?
}

\author{
Steven R. Messé, MD, ${ }^{a}$ and Karen L. Furie, $\mathrm{MD}^{\mathrm{b}}$ \\ From the ${ }^{\mathrm{a} D e p a r t m e n t}$ of Neurology, Hospital of the University of Pennsylvania, Philadelphia, Pa; and ${ }^{\mathrm{b}}$ Depart- \\ ment of Neurology, Brown University, Providence, RI. \\ Received for publication Oct 3, 2016; revisions received Nov 23, 2016; accepted for publication Dec 16, 2016; \\ available ahead of print June 20, 2017 \\ Address for reprints: Steven R. Messé, MD, Hospital of the University of Pennsylvania, 3400 Spruce St, 3 W \\ Gates Building, Philadelphia, PA 19104 (E-mail: messes@uphs.upenn.edu). \\ J Thorac Cardiovasc Surg 2017;154:880-3 \\ $0022-5223 / \$ 36.00$ \\ Copyright (C) 2017 by The American Association for Thoracic Surgery \\ http://dx.doi.org/10.1016/j.jtcvs.2016.12.075
}

Stroke is one of most devastating and dreaded complications of cardiothoracic procedures, associated with dramatically increased mortality, morbidity, and costs. ${ }^{1,2}$ Recent years have seen heightened awareness of the prevalence and impact of neurologic complications of surgery. Simultaneously, transcatheter aortic valve implantation (TAVI) has emerged as a major advance in the management of patients with calcific valvular disease, a condition that is becoming increasingly common owing to the aging of the population. TAVI has been demonstrated to be superior to conservative therapy in patients with severe aortic stenosis unsuitable for surgery, and to have generally similar or superior outcomes compared with open surgical aortic valve replacement (SAVR) in highrisk and moderate-risk patients. ${ }^{3-7}$ Long-term follow-up is continuing from earlier studies, and additional trials with low risk patients are now actively enrolling.

In general, although a transcatheter approach inherently reduces morbidity and shortens recovery times compared with traditional open heart surgery, the potential for complications remains a concern. Expanding a bioprosthetic valve into the calcific aortic annulus without achieving distal control via an aortic clamp can precipitate embolism to cerebral vessels, and, although far from a universal finding, some studies have reported an increased risk of stroke with TAVI compared with open SAVR. ${ }^{3,4}$ So, would a device that can protect the brain from emboli during TAVI be a "no brainer"? Of course! But designing an effective device and proving that it is beneficial will be major challenges.

Randomized trials of TAVI have reported 30-day clinical stroke rates ranging from $4 \%$ to $6.7 \%$ (Table 1). Interestingly, prospective nonrandomized registries in Europe have found lower 30-day stroke rates, ranging from 3.4\% to $4.1 \%$, and a large US registry has reported a rate of only $2.2 \%$, suggesting that some neurologic complications are going undetected or underreported in routine clinical practice. . $^{8-10}$

The reported rates of clinical neurologic events are directly related to the means of ascertainment. Some studies

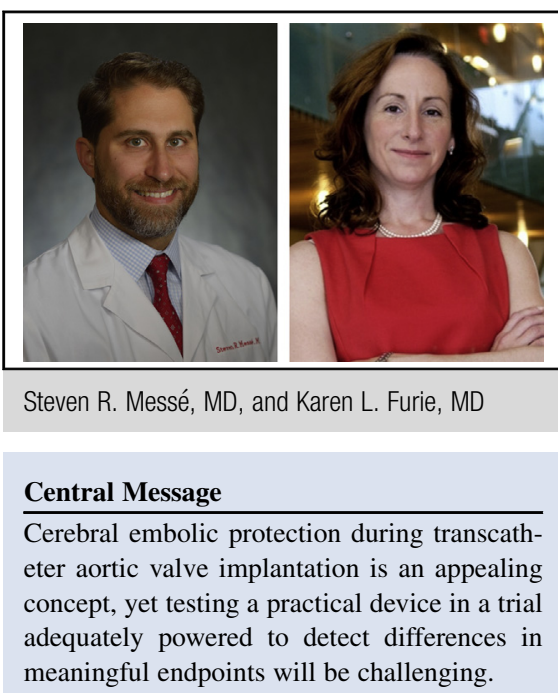

See Editorial Commentary page 884.

have used neurologists to perform assessments, but most have used non-neurologist physicians, advanced practice nurses, or research coordinators who have been credentialed in use of the National Institutes of Health Stroke Scale (NIHSS). Although the NIHSS is a reasonably thorough and validated neurologic assessment, it does not assess all neurologic function, and it has some limitations. ${ }^{11}$ Most importantly, the NIHSS does not definitively indicate whether or not a stroke occurred. There are little data to define best practice, but direct comprehensive assessment by a neurologist is likely the most accurate and sensitive method for detecting clinical stroke. Almost as important as who is doing the assessment is when the assessment occurs. In TAVI procedures, approximately one-half of the 30-day stroke events are detected within 2 days of the procedure. ${ }^{12}$ Because most early events are causally related to the intervention and symptoms generally improve over time, mild or transient symptoms will be missed if the only protocol-driven assessment occurs just before discharge. Unfortunately, in most studies, this is when the neurologic assessment is performed. Some cohorts in the PARTNER 2 study of intermediate risk patients did have 24-hour assessments by a neurologist, and they reported similar (for TAVI) or higher (for SAVR) stroke rates compared with the higher-risk patients in PARTNER 1, suggesting that performing an earlier assessment does influence the reported stroke rate. 
TABLE 1. Periprocedural clinical stroke rates and ascertainment methodology for various TAVI randomized trials

\begin{tabular}{|c|c|c|c|}
\hline Trial & TAVI stroke rate, $\%$ & SAVR stroke rate, $\%$ & Methodology \\
\hline CoreValve Extreme Risk ${ }^{6}$ & 4 & - & Assessment by coordinator at discharge and day 30 \\
\hline PARTNER I Extreme Risk ${ }^{3}$ & 6.7 & 1.7 & Assessment by physician or nurse at discharge and day 30 \\
\hline PARTNER I High Risk ${ }^{4}$ & 4.7 & 2.4 & Assessment by physician or nurse at discharge and day 30 \\
\hline CoreValve High Risk ${ }^{5}$ & 4.9 & 6.2 & Assessment by coordinator at discharge and day 30 \\
\hline PARTNER $2^{7}$ & 5.5 & 6.1 & Assessment by neurologist at $24 \mathrm{~h}$ (cohort A), discharge, and day 30 \\
\hline
\end{tabular}

TAVI, Transcatheter aortic valve implantation; SAVR, surgical aortic valve replacement; PARTNER, Placement of Aortic Transcatheter Valves.

\section{MAGNETIC RESONANCE IMAGING TO DETECT INFARCTS}

Whereas clinical assessment is necessary to identify stroke signs and symptoms, many patients who undergo TAVI experience subclinical ischemic injury that can be detected only on neuroimaging. Magnetic resonance imaging (MRI) is considerably more sensitive for detecting acute infarction than head computed tomography scan, especially for the small lesions frequently seen after cardiovascular procedures. ${ }^{13}$ Although MRI evidence of infarction might not be equivalent to clinically detected ischemic stroke, it is often very important. Within the past decade, the accepted definitions of stroke and transient ischemic attack (TIA) have changed from time-based (ie, TIA defined as neurologic symptoms due to ischemia lasting less than 24 hours) to tissue-based (ie, TIA defined as neurologic symptoms due to ischemia lasting less than 24 hours without evidence of infarct on neuroimaging). ${ }^{14}$ The most recent American Heart Association/American Stroke Association statement on the definition of stroke includes radiographic infarct following surgical and interventional procedures, even if that infarct is clinically silent. ${ }^{15}$ Studies of MRI performed early after TAVI have demonstrated acute infarcts in $68 \%$ to $97 \%$ of patients. ${ }^{16,17}$ In general, these infarcts tend to be small and multiple; in fact, most comparative studies have reported that the infarcts tend to be smaller but more numerous following TAVI compared with SAVR. ${ }^{18}$ These insults are not necessarily silent but rather may be manifested by subtle impairment of cognition, function, and quality of life that might not be immediately apparent. In the general population, microinfarcts seen on MRI have been associated with dementia, risk of stroke, and mortality ${ }^{19}$; however, it remains uncertain whether very small clinically silent infarcts on MRI after cardiovascular procedures have the same important long-term effects. ${ }^{20,21}$ Additional studies to assess the long-term implications of clinically silent infarcts are clearly needed.

A prospective observational study of 196 patients undergoing SAVR has highlighted the potential importance of acute infarct burden on periprocedural MRI. ${ }^{22}$ Subjects were assessed by neurologists on postoperative days 1, 3, and 7 and underwent MRI when possible on postoperative day 5. With this aggressive ascertainment and use of MRI, clinical stroke was identified in $17 \%$ of the subjects, although most cases were mild. More than one-half of the subjects without clinical symptoms had a silent radiographic infarct detected on MRI. Importantly, MRI infarct volume was strongly correlated with stroke severity based on NIHSS score $(\rho=0.57 ; P=.009)$, and compared with subjects with clinically silent lesions, those with clinical stroke symptoms had more infarcts (median, 1 vs 3; $P=.004$ ) and significantly larger infarct volumes (median, $284 \mathrm{~mm}^{3}$ vs $552 \mathrm{~mm}^{3} ; P=.02$ ). These findings suggest that improved outcomes could be achieved by reducing the number and volume of infarcts.

\section{TRIALS OF EMBOLIC PROTECTION}

A trial of stenting versus endarterectomy for symptomatic carotid stenosis provides a cautionary tale about cerebral embolic protection devices. Among patients who underwent angioplasty and stenting, those treated with a cerebral protection device were much more likely to have an acute infarct detected on MRI compared with those who did not receive a protection device $(73 \%$ vs $34 \%$; adjusted odds ratio, $2.70 ; 95 \%$ confidence interval, 1.16-6.24; interaction $P=.02) .^{23}$ The fact that the embolic protection device had to pass through the severely stenosed and recently symptomatic carotid artery likely led to additional cerebral emboli. Placing a cerebral protection device in the aorta for a TAVI procedure also could be problematic in the presence of severe aortic arch disease or variant anatomy. Some embolic protection devices proposed for use in TAVI do not cover all routes to the brain.

To date, only a handful of small pilot trials of embolic protection devices for TAVI have been reported, although additional studies are ongoing (Table 2). One study in which 30 patients undergoing transaortic TAVI were randomized to standard care or use of the EMBOL-X device (Edwards Lifesciences, Irvine, Calif), a filter that can be placed directly into the ascending aorta during a transaortic procedure, reported no significant difference in the number of new infarcts detected on MRI $(57 \%$ vs $69 \% ; P=.70)$ or in total infarct volume $\left(88 \pm 60 \mathrm{~mm}^{3}\right.$ vs $168 \pm 217 \mathrm{~mm}^{3}$; $P=.27){ }^{24}$ In another small study, the Embrella embolic deflection device (Edwards Lifesciences) was tested in 15 patients undergoing TAVI in comparison with 37 patients undergoing routine TAVI. ${ }^{25}$ The investigators found an increased number of radiographic cerebral infarcts in the 
TABLE 2. Completed and ongoing randomized studies of embolic protection devices in TAVI

\begin{tabular}{lccr}
\hline \multicolumn{1}{c}{ Trial and device } & ClinicalTrials.gov Identifier & Number of patients & Status \\
\hline Embol-X device for transaortic TAVI $^{24}$ & NCT01735513 & 30 & Completed \\
Embrella device $^{25}$ & - & 52 & Completed \\
DEFLECT III using the Triguard device & NCT02070731 & NCT01833052 & Completed \\
CLEAN-TAVI using the Montage device ${ }^{17}$ & NCT02214277 & 100 & Completed \\
SENTINEL trial using the Sentinel device & NCT02895737 & Completed \\
PROTECT-TAVI trial using the Sentinel device & NCT02536196 & 363 & Ongoing \\
REFLECT trial using the Triguard device & & 328 & Ongoing \\
\hline
\end{tabular}

TAVI, Transcatheter aortic valve implantation.

Embrella group (9.0 vs 5.0; $P=.044$ ), but smaller lesion volumes $(9.7 \mu \mathrm{L}$ vs $17.8 \mu \mathrm{L} ; P<.001)$.

The DEFLECT III study evaluated the TriGuard embolic deflection device (Keystone Heart, Caesarea, Israel) in 85 patients undergoing TAVI. ${ }^{26}$ This device, which covers the innominate, left common carotid, and subclavian arteries, thereby protecting all cervicocephalic vessels, was successfully placed in $89 \%$ of the subjects. The primary composite endpoint (death, stroke, lifethreatening or disabling bleeding, stage $>1$ acute kidney injury, or major vascular complications) occurred in $22 \%$ of the subjects who received the protection device and in $31 \%$ of controls $(P=.34)$. Among the $69 \%$ of subjects who underwent MRI after the procedure and had successful device placement with complete 3-vessel cerebral coverage, TriGuard use was associated with fewer new neurologic deficits detected by the NIHSS and possibly improved cognitive outcomes in some domains.

The CLEAN-TAVI trial used the Claret Montage Dual Filter System (Claret Medical, Santa Rosa, Calif) and focused on acute MRI infarctions as a surrogate outcome. ${ }^{17}$ The study randomized 100 patients, and as a proof-of-concept, investigator-initiated phase II study, the primary prespecified endpoint was the volume of infarcts within the vascular territories protected by the device, which included both carotids and the right vertebral artery. The number of new was reduced in patients who received the filter (median, 4.0 vs 10.0; difference, 5.00; interquartile range, 2.00-8.00; $P<.001$ ). Importantly, despite the unprotected left vertebral artery, there was an overall lower lesion volume when all brain regions were included in the assessment (mean, $242 \mathrm{~mm}^{3}$ vs $\left.527 \mathrm{~mm}^{3} ; P=.001\right)$. Clinical outcomes were not different, but the study was not powered to detect meaningful differences.

Finally, a recently published larger randomized study included 363 patients undergoing TAVI randomized to standard care or use of the SENTINEL dual filter system (Claret Medical). ${ }^{27}$ Neither postprocedure acute infarct volume $\left(178.0 \mathrm{~mm}^{3}\right.$ in controls vs $102.8 \mathrm{~mm}^{3}$ in the device arm; $P=.33$ ) or the rate of clinical ischemic stroke $(9.1 \%$ in controls vs $5.6 \%$ in the device arm; $P=.25)$ were statistically different between the 2 arms, although both estimates favored the device. Importantly, the authors reported that the risk of MRI-detected infarct varied among the different valve devices. In addition, although the authors did not report improved neurocognitive outcomes in patients who received the protection device, they did report a correlation between acute infarct volume on MRI and neurocognitive decline at 30 days postprocedure $(P=.003)$.

The foregoing studies highlight one of the major challenges of developing a cerebral embolic protection device for use in TAVI: designing a trial that can prove a clinical benefit. Major strokes complicating TAVI, although troubling, are sufficiently rare such that a very large, properly powered trial will be needed to detect a clinically meaningful reduction in this outcome. MRI is very sensitive to brain injury, and significant reductions in infarct number and volume may be important, but as noted above, the clinical correlate of small infarcts discernable only on MRI remains unclear. The association between MRIdetected infarct volume and cognitive decline at 30 days postprocedure seen in the SENTINEL trial is important, but the long-term sequelae remain uncertain, and additional data are required. Thus, ideally studies of embolic protection for TAVI need to be adequately powered, stratify by the type of valve being used, incorporate early and repeated neurologic assessments to increase the sensitivity for clinical events, use MRI to help accurately classify clinical symptoms and quantify infarct burden, and evaluate other clinically important outcomes, such as neurocognitive function, depression, and quality of life. Multiple larger trials of embolic protection for TAVI are currently ongoing, and the field eagerly awaits these results.

\section{CONCLUSIONS}

At least in theory, cerebral embolic protection during TAVI is a "no brainer." Embolic protection is an intuitive and appealing concept, and some of the pilot data appear promising. Nevertheless, there are significant challenges to overcome before embolic protection becomes routine in clinical practice. Developing a practical and safe device and testing it in a trial adequately powered to detect differences in radiographic and clinically meaningful endpoints 
is not a trivial task; however, there is no doubt that a device proven to reduce radiographic infarction and improve clinical outcomes will make TAVI a safer and even more desirable option for patients.

\section{Conflict of Interest Statement}

Dr Messé has received research support for his work on a trial of neuroprotection during thoracic aortic repair from GlaxoSmithKline and for his role as a subinvestigator in the National Institutes of Health (NIH)/National Heart, Lung, and Blood Institute (NHLBI)/National Institute of Neurologic Disorders and Stroke (NINDS)-sponsored Cardiothoracic Surgery Network, which has performed research on neuroprotection during aortic valve surgery. He has also received support for his role on the Clinical Event Committee for the SALUS trial sponsored by Direct Flow Medical, Inc. Dr Furie has received research support for her role on the Event Adjudication Committee and Writing Committee for the NIH/NHLBI/NINDS-sponsored Cardiothoracic Surgery Network, which has performed research on neuroprotection during aortic valve surgery.

\section{References}

1. Puskas JD, Winston AD, Wright CE, Gott JP, Brown WM III, Craver JM, et al. Stroke after coronary artery operation: incidence, correlates, outcome, and cost. Ann Thorac Surg. 2000;69:1053-6.

2. Salazar JD, Wityk RJ, Grega MA, Borowicz LM, Doty JR, Petrofski JA, et al. Stroke after cardiac surgery: short- and long-term outcomes. Ann Thorac Surg. 2001;72:1195-201; discussion 1201-2.

3. Leon MB, Smith CR, Mack M, Miller DC, Moses JW, Svensson LG, et al. Transcatheter aortic-valve implantation for aortic stenosis in patients who cannot undergo surgery. N Engl J Med. 2010;363:1597-607.

4. Smith CR, Leon MB, Mack MJ, Miller DC, Moses JW, Svensson LG, et al. Transcatheter versus surgical aortic-valve replacement in high-risk patients. $N$ Engl $J$ Med. 2011;364:2187-98.

5. Adams DH, Popma JJ, Reardon MJ, Yakubov SJ, Coselli JS, Deeb GM, et al. Transcatheter aortic-valve replacement with a self-expanding prosthesis. $N$ Engl J Med. 2014;370:1790-8.

6. Popma JJ, Adams DH, Reardon MJ, Yakubov SJ, Kleiman NS, Heimansohn D, et al. Transcatheter aortic valve replacement using a self-expanding bioprosthesis in patients with severe aortic stenosis at extreme risk for surgery. J Am Coll Cardiol. 2014;63:1972-81.

7. Leon MB, Smith CR, Mack MJ, Makkar RR, Svensson LG, Kodali SK, et al. Transcatheter or surgical aortic-valve replacement in intermediate-risk patients. N Engl J Med. 2016;374:1609-20.

8. Gilard M, Eltchaninoff H, Iung B, Donzeau-Gouge P, Chevreul K, Fajadet J, et al. Registry of transcatheter aortic-valve implantation in high-risk patients. $N$ Engl J Med. 2012;366:1705-15.

9. Moat NE, Ludman P, de Belder MA, Bridgewater B, Cunningham AD, Young CP, et al. Long-term outcomes after transcatheter aortic valve implantation in high-risk patients with severe aortic stenosis: the U.K. TAVI (United Kingdom Transcatheter Aortic Valve Implantation) Registry. J Am Coll Cardiol . 2011;58:2130-8.

10. Holmes DR Jr, Nishimura RA, Grover FL, Brindis RG, Carroll JD, Edwards FH, et al. Annual outcomes with transcatheter valve therapy: from the STS/ACC TVT Registry. Ann Thorac Surg. 2016;101:789-800.
11. Martin-Schild S, Albright KC, Tanksley J, Pandav V, Jones EB, Grotta JC, et al Zero on the NIHSS does not equal the absence of stroke. Ann Emerg Med. 2011 $57: 42-5$.

12. Kapadia S, Agarwal S, Miller DC, Webb JG, Mack M, Ellis S, et al. In sights into timing, risk factors, and outcomes of stroke and transient ischemic attack after transcatheter aortic valve replacement in the PARTNER trial (Placement of Aortic Transcatheter Valves). Circ Cardiovasc Interv. 2016;9:e002981.

13. Brazzelli M, Sandercock PA, Chappell FM, Celani MG, Righetti E, Arestis N, et al. Magnetic resonance imaging versus computed tomography for detection of acute vascular lesions in patients presenting with stroke symptoms. Cochrane Database Syst Rev 2009;4:CD007424.

14. Easton JD, Saver JL, Albers GW, Alberts MJ, Chaturvedi S, Feldmann E, et al Definition and evaluation of transient ischemic attack: a scientific statement for healthcare professionals from the American Heart Association/American Stroke Association Stroke Council; Council on Cardiovascular Surgery and Anesthesia; Council on Cardiovascular Radiology and Intervention; Counci on Cardiovascular Nursing; and the Interdisciplinary Council On Peripheral Vascular Disease. Stroke. 2009;40:2276-93.

15. Sacco RL, Kasner SE, Broderick JP, Caplan LR, Connors JJ, Culebras A, et al. An updated definition of stroke for the 21st century: a statement for healthcare professionals from the American Heart Association/American Stroke Association. Stroke. 2013;44:2064-89.

16. Arnold M, Schulz-Heise S, Achenbach S, Ott S, Dörfler A, Ropers D, et al Embolic cerebral insults after transapical aortic valve implantation detected by magnetic resonance imaging. JACC Cardiovasc Interv. 2010;3:1126-32.

17. Haussig S, Mangner N, Dwyer MG, Lehmkuhl L, Lucke C, Woitek F, et al. Effect of a cerebral protection device on brain lesions following transcatheter aortic valve implantation in patients with severe aortic stenosis: The CLEAN-TAVI randomized clinical trial. JAMA. 2016;316:592-601.

18. Kahlert P, Knipp SC, Schlamann M, Thielmann M, Al-Rashid F, Weber M, et al Silent and apparent cerebral ischemia after percutaneous transfemoral aortic valve implantation: a diffusion-weighted magnetic resonance imaging study. Circulation. 2010;121:870-8.

19. Smith EE, Schneider JA, Wardlaw JM, Greenberg SM. Cerebral microinfarcts: the invisible lesions. Lancet Neurol. 2012;11:272-82.

20. Meller SM, Baumbach A, Brickman AM, Lansky AJ. Clinical implications for diffusion-weighted MRI brain lesions associated with transcatheter aortic valve replacement. Catheter Cardiovasc Interv. 2014;83:502-8.

21. Patel N, Minhas JS, Chung EM. The presence of new MRI lesions and cognitive decline after cardiac surgery: a systematic review. J Card Surg. 2015;30; 808-12.

22. Messé SR, Acker MA, Kasner SE, Fanning M, Giovannetti T, Ratcliffe SJ, et al Stroke after aortic valve surgery: results from a prospective cohort. Circulation. 2014;129:2253-61.

23. Bonati LH, Jongen LM, Haller S, Flach HZ, Dobson J, Nederkoorn PJ, et al. New ischaemic brain lesions on MRI after stenting or endarterectomy for symptomatic carotid stenosis: a substudy of the International Carotid Stenting Study (ICSS). Lancet Neurol. 2010;9:353-62.

24. Wendt D, Kleinbongard P, Knipp S, Al-Rashid F, Gedik N, El Chilali K, et al. Intraaortic protection from embolization in patients undergoing transaortic transcatheter aortic valve implantation. Ann Thorac Surg. 2015;100 686-91.

25. Samim M, Agostoni P, Hendrikse J, Budde RP, Nijhoff F, Kluin J, et al. Embrella embolic deflection device for cerebral protection during transcatheter aortic valve replacement. J Thorac Cardiovasc Surg. 2015;149:799-805. e1-2.

26. Lansky AJ, Schofer J, Tchetche D, Stella P, Pietras CG, Parise H, et al. A prospective randomized evaluation of the TriGuard HDH embolic DEFLECTion device during transcatheter aortic valve implantation: results from the DEFLECT III trial. Eur Heart J. 2015;36:2070-8.

27. Kapadia SR, Kodali S, Makkar R, Mehran R, Lazar RM, Zivadinov R, et al. Protection against cerebral embolism during transcatheter aortic valve replacement. J Am Coll Cardiol. 2017;69:367-77. 